\title{
REFLEXIONES SOBRE LA CONSTITUCIÓN SINCRÉTICA DEL TRABAJO SOCIAL EN AMÉRICA LATINA ${ }^{1}$
}

\section{Freddy Esquivel Corella ${ }^{2}$}

\section{Resumen}

El tema del sincretismo en el Trabajo Social latinoamericano no es de frecuente debate en la profesión, el presente artículo busca destacar brevemente algunas de las bases que lo constituyen, generando aportes a las reflexiones latinoamericanas vinculadas a la profesión.

Descriptores: Trabajo Social, América Latina, sincretismo escolástica, positivismo, reformismo, marxismo, fenomenología, pragmatismo, protestantismo, eclecticismo.

\section{Abstract}

The subject of the philosophy in the Latin American Social Work is not of frequent debate in the profession, the present article looks for to briefly emphasize some of the bases that constitute it, generating contributions to the tie Latin American reflections to the profession.

Keywords: Social Work, Latin America, philosophy.

' Profesor en la Escuela y Maestría de Trabajo Social, Universidad de Costa Rica.

2 Quisiera dedicar este breve trabajo a las colegas de Panamá, especialmente a la Asociación Panameña de Trabajadoras Sociales, quienes han demostrado un serio compromiso con la profesión y su constante autocrítica. 


\section{Introducción}

Se puede considerar en un artículo de esta naturaleza, que las bases o fundamentos teórico-metodológicos que se expresan en el Trabajo Social en América Latina, tienen dos influencias históricas determinantes en la herencia de su constitución, ellas son la europea y norteamericana (Martinelli, 1995). Esto significa que en los países donde se dio un contacto más estrecho con las colonias europeas, el legado de ese continente se dejó sentir con mayor presencia, hablamos aquí de Chile, Brasil, Argentina y Uruguay principalmente.

Por su lado los países que fueron parte de la influencia norteamericana en trabajo social, como Centroamérica ${ }^{3}$, países del Caribe, Panamá, Colombia, Ecuador, Perú, Bolivia, entre otros, tuvieron una intensa presencia del legado que esa nación diseminó en el continente, a pesar de la herencia española y los tintes del viejo continente. Zea (1976) destaca al respecto:

El Mundo Iberoamericano, colonizado por España y Portugal, entra en el siglo XIX en la más extraña aventura, en donde un conjunto de pueblos pueda entrar en el campo de las ideas: la aventura que significa tratar de deshacerse de la propia formación cultural para adoptar otra. [...] Caminos que, ante los sorprendidos ojos iberoamericanos, se presentaban como opuestos y casi inconciliables con los que ellos habían recibido como herencia. Inglaterra con su revolución industrial y sus instituciones políticas; Francia con su revolución política e ideológica, y los Estados Unidos con sus nuevas instituciones de carácter liberal y democrático, mostraban otras rutas al mundo (pág. 179).

Lo anterior conlleva a reflexionar que en el momento en que se constituye la profesión de Trabajo Social en América Latina, producto de las consecuencias de la crisis del capital de 1929, y de

\footnotetext{
${ }^{3}$ Exceptuando a Belice que mantuvo un contacto fuerte con Inglaterra, pasando luego de a ser parte de Guatemala, y posteriormente convertirse en un país independiente, pero siempre con su herencia colonial británica.
} 
la expresión más sólida del capitalismo monopolista en la región, la profesión va a tener configuraciones con diferencias importantes en los bloques de países citados. Mandel (1977) agrega al respecto:

La gran crisis económica de 1929 modificó fundamentalmente, en primer lugar, la actitud de la burguesía y de sus ideólogos con respecto al Estado; a continuación modificó la actitud de esta misma burguesía con relación a su propio régimen. [...] Pero no hay la menor duda de que el año 1929 y el período que siguió a la gran crisis de 1929-1932, sufrió una experiencia traumatizante para la burguesía norteamericana, burguesía que dentro de toda la clase capitalista mundial, era la única que sentía una confianza total, ciega, en el porvenir del régimen de la 'libre empresa'. Durante esta crisis de 1929-1932, sufrió un terrible choque que en verdad, para la sociedad americana constituyó la toma de conciencia de la cuestión social y el inicio del proceso del régimen capitalista, que, a grandes rasgos, corresponde a los que se había vivido en Europa durante el nacimiento del movimiento obrero socialista, en el período 1865-1890 del siglo pasado. (pág.80) (Negrilla no es del original).

Ese contexto histórico del modo de producción determinó de manera fundamental el abandono del capitalismo competitivista, y se dio un fortalecimiento por la búsqueda de la monopolización del capital, vale agregar al respecto:

La concentración de la producción conduce directamente a la formación de los monopolios. A las grandes empresas, poseedoras de cuantiosos capitales, les resulta difícil imponerse las unas a las otras en la lucha de la competencia. En estas condiciones surge la posibilidad y la necesidad de que se pongan de acuerdo al objeto de repartirse los mercados de venta y las fuentes de materias primas, establecer precios únicos, etc. El monopolio es el acuerdo o la agrupación de capitalistas que concentran

en 
sus manos la producción o la venta (y en muchos casos una y otra cosa) de la mayor parte de unas u otras mercancías. (Nikin, 1969: 144-145)

Dichos referentes conducen a reconocer que las transformaciones en el capitalismo, llevaron también un fortalecimiento de la necesaria tarea imperialista, en todos los campos de la sociedad, los fundamentos filosóficos que sustentaron y aún son mayoritariamente vigentes en Trabajo Social son muestra de ello; los cuáles se sincretizan con la herencia histórico intelectual del continente. Por lo tanto, los insumos del positivismo, el marxismo y la fenomenología también se expresan de manera diferenciada en la fundamentación teórico metodológica en Trabajo Social, reflejándose en la historia, de manera importante, la influencia del pragmatismo norteamericano, el protestantismo, y en el caso de la herencia europea se refleja con más fuerza la escolástica y el reformismo, cabe agregar que en este escenario aparece también el eclecticismo con diferentes expresiones.

Valga hacer la advertencia de que por la falta de investigación profunda sobre cada uno de estos temas, este artículo se orienta a elaborar conjeturas que requieren mayores insumos, pero que son coordenadas de orientación inicial. Además es necesario destacar aquí, que es por la naturaleza sincrética del contexto que se identifica en América Latina y en la profesión propiamente, que se dan esas complejas, y a veces contradictorias articulaciones, en que se constituyó la profesión de Trabajo Social (Netto, 1992); ello no fue resultado de sus agentes o su mera voluntad subjetiva. 


\section{El sincretismo en el Trabajo Social}

El sincretismo localizado en la profesión, puede ser de orientación teórico, político, ideológico, metodológico, económico y cultural (de todas maneras son en sí inseparables).

Netto (1992) es el investigador que incorpora por primera vez el tema del sincretismo en la base constitutiva de la profesión, específicamente en lo ideológico y lo teórico-metodológico. En la complejidad ideológica se destaca la influencia de la tradición cultural europea (especialmente la continental) y la norteamericana, de por sí ya profundamente heterogéneas y sincréticas. Estas dos líneas ideológicas ganaron hegemonía que les permitió moldear el perfil ideo político de la profesión, donde se reconoce que ellas mismas son resultantes de choques entre tendencias diferenciadas. La diferenciación entre ambas ideologíaś, se resume a continuación:

[...]en las fuentes ideológicas de las protoformas y de la afirmación inicial del Servicio Social europeo, dado el capitalismo romántico, hay un vigoroso componente de apología indirecta del capitalismo; en las fuentes norteamericanas ni siquiera de esta forma el orden capitalista era objeto de cuestionamiento (Netto, 1992: 115).

El sincretismo de la tradición europea estaba dado en la amalgama que buscaba fusionar una postura restauradora con algún grado de intervención. Inmanentemente, el anticapitalismo romántico se debate entre la extrema restauración [...] y soluciones intermediarias que obligatoriamente derivan en el sincretismo ideológico [...] [y el norteamericano] [...] está atravesada por el sincretismo [...] está inscrito en la configuración de un paradigma intelectual que debe atender a dos demandas de diverso sentido: por un lado, debe producir su legitimación racional en un medio socicultural muy adverso de 
elaboraciones intelectuales; por otro lado, debe constituirse bajo la subordinación" (Netto, 1992:118-119).

Estas dos vertientes sincréticas son las que inciden principalmente en las primeras representaciones éticas en la profesión; ello provocó que se reprodujera en un campo cultural-ideológico, que registraba un movimiento entre las dos tradiciones antes citadas, y otro situado en la relación entre cada una de ellas y las nuevas configuraciones que surgían en éstas, especialmente en el contexto latinoamericano y sus múltiples singularidades andinas, sureñas y centroamericanas. Es determinante señalar que en ese marco sincrético ideológico constitutivo del Trabajo Social, se dio predominancia en América Latina al legado de Tomás de Aquino, pasando luego a la construcción de lo que Netto (1992), llama una "nueva escolástica", que es el neotomismo.

Lo anterior, de acuerdo a Netto (1995) para:

[...] ofrecer un calce más consistente a la Iglesia de sus enfrentamientos, también por la vía de la Doctrina Social, con la modernidad $[\ldots]$ se inserta en un largo proceso de movilización de la Iglesia para hacer frente, teórica, doctrinaria y prácticamente, a los desafíos intelectuales, científicos políticos e ideológicos puestos, por un lado por el desarrollo científico y filosóficos, y, por otro, por la laicización de las instituciones sociales burguesas y por el movimiento obrero orientado por el marxismo y por el magnetismo desencadenado por la primera experiencia de tradición socialista" (págs. 124125).

Según lo anotado, el neotomismo, sin desprenderse de la tradición conservadora, vino a incidir en la formación y práctica del Trabajo Social, y por ende en su referente ético y teórico metodológico. Se rechazaron en su constitución las propuestas del movimiento obrero revolucionario y del socialismo, y por ende también se expulsan 
común", con respuestas técnico-administrativas, psicologizadoras y desarrollistas entre muchas otras, especialmente de corte reformista.

De esta manera, Netto (1992) afirma lo siguiente:

El sincretismo nos parece ser el hilo conductor de la afirmación y del desarrollo del Servicio Social como profesión, su núcleo organizativo y su norma de actuación. Se expresa en todas las manifestaciones de la práctica profesional y se revela en todas las intervenciones del agente profesional como tal. El sincretismo fue un principio constitutivo del Servicio Social. (pág. 89)

Dicho sincretismo se va a expresar en la base de la intervención profesional, sus fundamentos teórico-metodológicos y técnicooperativos (así como ético-políticos), no escaparon a teñirse de diversas bases que legitimaban una práctica sincrética. A ello vale anotar lo siguiente:

Es propio de la práctica que se toma sincréticamente, no solamente su traslación y aplicación a todo y cualquier campo y/o ámbito, reiterando procedimientos formalizados abstractamente y relevando su indiferenciación operativa. Combinando sentido común, buen sentido y conocimientos extraídos de contextos teóricos; manipulando variables empíricas según prioridades establecidas por la vía de la inferencia teórica o de voluntad burocrático-administrativa; legitimado su intervención con un discurso que mezcla valoraciones de las más diferentes especies, objetivos políticos y conceptos teóricos; recurriendo a procedimientos técnicos y cursos institucionales y a reservas de emergencias episódicas- realizada y pensada a partir de la estructura heteróclita, la práctica sincrética expone la aparente polivalencia. Esta no resulta sino del sincretismo práctico-profesional: se nutre de él y lo expresa en todas sus manifestaciones (Netto, 1992: 105). 
En síntesis, el sincretismo fue constitutivo de la profesión, en el marco del capitalismo monopolista, la profesión de Trabajo Social se constituyó bajo influencias de cariz europeo, estadounidense, y expresa tensiones importantes en las propias condiciones históricas de Latinoamérica (reflejadas con mayor profundidad local en la época de la Reconceptualización), con sus particularidades regionales y nacionales. Se proyecta sin duda, una profesión de compleja explicación cuando se abordan sus fundamentos filosóficos; aquí las explicaciones simplistas de la profesión empiezan a quedar sin fundamentos, y los argumentos analíticos requieren un fundamento complejo y sustentado.

Seguidamente se analizan algunas de las bases localizadas en el sincretismo más identificable en la literatura de primera mano, se cita ahí:

- La escolástica: herencia de la presencia de la Iglesia católica en muchas escuelas de Trabajo Social

- El positivismo: vinculado al desarrollo liberal de los estados y como base filosófica de la sociedad burguesa.

- El reformismo social cristiano: eje teórico de muchas líneas formativas en Trabajo Social, posterior a la crisis capitalista de 1929.

- El marxismo: vinculado a la experiencia de Reconceptualización, aunque no por medio de sus fuentes originales.

- La fenomenología: colocada como una vía en los momentos de crisis política como las dictaduras; además de ser influencia de la llamada clínica o terapia en Trabajo Social.

- El pragmatismo: sistema filosófico norteamericano, vinculado con el utilitarismo, y de impacto en la formación profesional, especialmente por parte de la ONU, la OEA y sus asesores académicos en las universidades.

- El protestantismo: como base de cierta herencia europea que se expresa en algunos países especialmente de Estados 
no confesionales; igualmente en parte de las bases del desarrollo de la clásica obra de Mary Richmond)

- El eclecticismo: planteamiento de quienes por no tomar posición en una teoría social, alegan tener la fundamentación para construir y reconstruir las bases filosóficas del trabajo profesional, sin encontrar contradicción, muy propio de los discursos posmodernos.

\section{La escolástica en Trabajo Social}

Entre las bases sincréticas de influencia europea en el Trabajo Social, se encuentra uno de los pilares fundamentales de las sociedades burguesas, se habla aquí de la escolástica. Es necesario aclarar, que antes de la predominancia del positivismo para la explicación de la sociedad, se identificaba en América Latina, la hegemonía de la base conceptual-ideológica que residía en la escolástica; la cual provenía también de Europa, y fue difundida por los españoles, y que de hecho, se mantuvo con particularidad luego del posicionamiento del positivismo.El capitalismo como modo de producción, les permitía a la escolástica y el positivismo tener esa movilidad y articulación, ya que ninguna de las dos expresaba total oposición al mismo (aunque se denotaban contradicciones, véase el famoso ejemplo de los jesuitas $\mathrm{y}$ los liberales).

Por escolástica entendemos un conjunto de sistemas filosóficos de origen europeo, de tendencia religiosa, que busca la relación de la teología con la filosofía. Cabe agregar:

El sistema consiste en un cuerpo doctrinal, lógicamente estructurado, en el que quedan justificados todos los elementos de una cosmovisión que acepte la revelación y la tradición cristiana. La escolástica, característica de la sociedad cristiana medieval, experimentó un renacimiento en los SS. XIX y XX en la corriente neoescolástica, que debe su formación como movimiento organizado a una bula del papa León XIII aconsejando la vuelta al tomismo [...] (Salvat, 2004: 5.360). 
Sobre la escolástica también Salazar (1988) señala:

El proceso del pensamiento filosófico hispanoamericano comienza con la introducción de las corrientes predominantes en la España de la época de la conquista, [...] Se traen a América y se propagan en nuestros países aquellas doctrinas que armonizaban con los propósitos de dominación política y espiritual que persiguen los órganos del poder temporal y espiritual de la península. [...] Salvo esporádicas y a veces heroicas apariciones de doctrinas que tenían más filo crítico y menos compromisos con el poder establecido -como el platonismo renacentista y el humanismo erasmista- la filosofía oficialmente difundida y protegida fue la Escolástica, en su tardía versión española, [...] El predominio de la Escolástica se prolonga -con variantes locales y mayor o menor intensidad- hasta el siglo XVIII (pág.12).

Finalmente cabe complementar sobre ello lo siguiente:

En Hispanoamérica durante la primera mitad de la época colonial reina sin seria contradicción la Filosofía Escolástica. Dominicos, franciscanos y jesuitas se disputan el predominio en el campo de las ideas: Santo Tomás, Duns Escoto y Suárez son los grandes nombres cuya autoridad se invoca (Insua, 1949: 13).

La escolástica no acabó con la hegemonía y fortalecimiento del positivismo como base para explicar la sociedad liberal, lo anterior, ya que existió una tensa convivencia entre positivismo y escolática; otro ejemplo de ello son las historias de países como Uruguay, Guatemala y Costa Rica que reflejan tensiones entre las relaciones de la Iglesia Católica y los políticos liberales del siglo XIX. Dicha Iglesia se mantuvo en algunos países como institución de poder y control social, en alianzas estratégicas con liberales y conservadores, conduciendo al establecimiento de las relaciones 
capitalistas; además la Iglesia, por su base tomista y neotomista jugó incluso un papel de legitimadora indirecta del positivismo, aunque de una forma crítica.

Debe recordarse que el tomismo fundamentalmente de caracteriza por ser:

[...] un conjunto de normativas impuestas por la religiosidad católica. El objetivo de la vida no es más la felicidad [...], pero sí la salvación individual. La existencia ética, igual que implica obligaciones comunitarias- amor al prójimo, caridad, abnegación, fraternidad-, tiene como referencia prioritaria la preparación de la redención del individuo después de la muerte. La plena realización humana obtenida por el cumplimiento de los valores, sólo se dará por tanto en el mundo supraterreno, en el reino del cielo (Augusto, 1995: 107).

La escolástica no es la misma desde la implantación del imperio español católico en América Latina, ya que se fue discutiendo y argumentando con insumos propios de sus debates doctrinales y los desafíos que le presenta la ciencia a la religión, los aportes de Newton fueron fuente de rejuvenecimiento escolástico. La base tomista y neotomista fue la piedra angular de la filosofía de la Iglesia, que se impregna en el Trabajo Social para explicar el principal objeto de trabajo profesional, o sea la "cuestión social", tal y como lo demuestra la obra de algunos Papas pero especialmente de León XIII y Pío XI en sus respectivas encíclicas. Netto (1992) destaca lo siguiente:

[...] un calce más consistente a la Iglesia de sus enfrentamientos, también por la vía de la Doctrina Social, con la modernidad [...] se inserta en un largo proceso de movilización de la Iglesia para hacer frente, teórica, doctrinaria y prácticamente, a los desafíos intelectuales, científicos políticos e ideológicos puestos, por un lado por el desarrollo científico y filosóficos, y, por otro, por la laicización de las instituciones sociales burguesas y por el 
movimiento obrero orientado por el marxismo y por el magnetismo desencadenado por la primera experiencia de tradición socialista (Págs. 124-125).

De igual manera, Iamamoto (1992) agrega:

Nuestra herencia intelectual fue marcada por la doctrina social de la Iglesia y por el moderno conservadurismo europeo en sus orígenes, incorporándose más tarde la sociología funcionalista norteamericana de raíz fuertemente empiricista. Ese legado técnico-doctrinario fue el hilo que recorre el tradicionalismo profesional, con cohesión tanto de las interpretaciones de la sociedad como del campo de los valores norteadores de la acción (pág. 8).

Cabe señalar que también la filosofía católica, particularmente la neotomista, ha sido muy divulgada y tiene un firme bastión en las universidades y escuelas superiores católicas y otras instituciones auspiciadas por la Iglesia (Salazar, 1988); su proyección en las organizaciones gremiales como colegios y asociaciones profesionales no es nada despreciable. Igualmente es necesario recordar, que esto no es propio de América Latina, ya que estas cuestiones se venían expresando, con sus singularidades en el Servicio Social europeo, que es la fuente de donde potencialmente se hereda este fundamento, léase al respecto:

Burguesía, Iglesia y Estado se unieron en un compacto y reaccionario bloque político, intentando cubrir las manifestaciones de los trabajadores euroccidentales [...], impedir sus prácticas de clase y ahogar su expresión política y social. En Inglaterra, el resultado material y concreto de esa unión fue el surgimiento de la Sociedad de Organización de la Caridad [C.O.S, de origen evangélico] de Londres, en 1869, congregando los reformistas sociales que pasaban ahora a asumir formalmente, frente a la sociedad burguesa constituida, la responsabilidad por la racionalización y la normatización de la práctica de la 
asistencia. Surgían así, en el escenario histórico, los primeros asistentes sociales, como agentes ejecutores de la práctica de la asistencia social, actividad que se profesionalizó bajo la denominación de "Servicio Social", acentuando su carácter de práctica de prestación de servicios (Martinelli, 1997: 71).

A diferencia de Europa, en América Latina es la Iglesia Católica la que gana terreno articulándose con la burguesía y el Estado; estos vínculos se construyeron a la luz de la profundización del pensamiento positivista en el continente.

\section{El positivismo en Trabajo Social}

Los avances del pensamiento independentista liberal en América Latina, marcaron una fuerte crítica a los fundamentos de la escolástica, lo anterior provocado desde los debates que el positivismo había posibilitado en la legitimación del capitalismo, a nivel europeo, extendiéndose a otras partes del mundo. Sobre el positivismo en América Latina, Soler (1979) plantea:

Desde el punto de vista de la evolución inmanente de las ideas habría de considerarse el pensamiento hispanoamericano de mediados del XIX como una proyección sui géneris de las corrientes ideológicas que en Europa desembocaron en el positivismo de Comte, y en el evolucionismo de Spencer (pág. $38)$.

Valga hacer la aclaración de que las bases filosóficas europeas y norteamericanas en América Latina se manifiestan de forma diferente a lo largo del continente, sumado a ello están las particularidades de Brasil que fue producto del imperio portugués; por lo que la mayoría de los aportes que aquí se hacen son de referencia principal para los países de lengua castellana. 
Aunado a este tema se destaca:

Entre los años 1880 y 1900 pareció surgir una Hispanoamérica nueva. [...] Un nuevo orden se alzaba en cada país; pero ya no era el orden colonial, sino un orden apoyado en las ideas del progreso y la ciencia. [...] La filosofía que justificó este orden y sirvió de orientación en esta nueva forma de educación, fue el positivismo. Sirviéndose del positivismo, los mexicanos creyeron que daban término a la anarquía que les había azotado desde la Independencia. Los argentinos vieron en esta filosofía un buen instrumento para imposibilitar el resurgimiento de las mentes absolutistas y tiránicas que los habían oprimido. Los chilenos en su marcha casi evolutiva, hallaron en el mismo un medio eficaz para realizar plenamente sus ideas liberales. En el Uruguay el positivismo se presentó como una doctrina moral capaz de poner término a la larga era de cuartelazos y corruptelas. Perú y Bolivia encontraron en él la enseñanza que habría de fortalecerles después de la catástrofe nacional que sufrieron en su guerra contra Chile. Para los cubanos fue la filosofía que habría de justificar su afán de independencia frente a España. En el resto de Hispanoamérica constituyó el sistema para terminar con el predominio de las viejas fuerzas clericales y despóticas. En fin, todos los países vieron en él el instrumento que iba a permitirles, por fin, incorporarse al progreso en forma semejante a la de los pueblos que tanto habían admirado y que ahora temían. Comte, Stuart Mill y Spencer, fueron los filósofos positivistas que mayor influencia tuvieron en estas ideas. Sin embargo, esta influencia dependió, en cada caso, de las circunstancias a las cuales se hicieron servir." [...] En el Brasil, por el contrario, el positivismo no vino a justificar un ideal más como en Hispanoamérica. Siguiendo su marcha esta nación, [...] se encontró con el positivismo y se sirvió de él por considerarlo adecuado a las nuevas circunstancias, [...] El positivismo se presentó en el Brasil como el mejor de los instrumentos para frenar dos fuerzas que hubieran podido llevarlo hacia extremos: la Iglesia y la masonería. [...] La influencia del 
positivismo en la República se hizo sentir en varios aspectos, empezando por el formato de la bandera que adopta el lema comtiano de 'Orden y Progreso' (Zea, 1976: 201, 202 y 203).

La influencia del positivismo en el Trabajo Social, tal y como se ha destacado en anteriores apartados, está relacionada con la base filosófica societal que se impone en los países del continente, teniendo este legado, la tarea de respaldar el establecimiento de las relaciones capitalistas, por lo que es entendible, que el positivismo fuera la plataforma en los primeros fundamentos en la profesión, recuérdese que la primera materialización de un centro de formación en Trabajo Social fue en Chile a mediados de los años veinte del siglo pasado, ya existía una madurez intelectual en la base liberal del continente. Este escenario se constituyó de influencias escolásticas, positivistas y reformistas, propuesta que viene a enraizarse para posibilitar el surgimiento de Escuelas de Servicio Social, en países como Costa Rica, Panamá, Uruguay y Argentina, para citar algunas.

\section{El reformismo en Trabajo Social}

En la conjugación de contradicciones entre la escolástica y el positivismo, se va a encontrar, iniciado el siglo XX, una nueva corriente que tiene relevancia para el Trabajo Social, la cual es el reformismo. El mismo se puede definir desde Brand (1995) como:

Corriente oportunista con alcances muy limitados que se acomodan a los intereses inmediatos de la pequeña burguesía, que niega la lucha revolucionaria del proletariado. Los reformistas se esfuerzan por contener las luchas revolucionarias aplicando una política de conciliación de las contradicciones de clase, colaborando con la burguesía en la realización de reformas parciales que no afectan los fundamentos del capitalismo ni la naturaleza del régimen estatal burgués (Pág; 670). 
Aunque también se conceptúa como: "Doctrina política socialista, de carácter moderado, que procura la instauración gradual de las ideas socialistas, desde los medios proporcionados por las instituciones políticas democráticas" (Océano Uno: 1990 - 1120).

El reformismo va a ser una base ideológico-política que va marcar pautas importantes en las explicaciones y abordajes que se manifiestan en las devastaciones de la "cuestión social", y sobre la cual se van a edificar algunos de los currículos de Trabajo Social, Castro e Iamamoto (1979) agregan al respecto:

El Trabajo Social como profesión aparece en la década de los años 1920 y 1930 como resultado y directamente vinculado a entidades religiosas que asumen la creación de escuelas de formación profesional y se constituyen de ese modo en las primeras instancias organizadas de preparación de cuadros profesionales. Su ingreso a las aulas universitarias, a diferencia de otras profesiones de carácter más técnico y de mayor entronque con el nivel de desarrollo de la economía, tiene lugar como resultado de un fenómeno de tipo ideológico impulsado por la concepción humanitaria y filantrópica ejercida por representantes de sectores de las clases dominantes, posiblemente vinculados a una suerte de aristocracia agroexportadora, directamente relacionados con la iglesia que era portadora de un mensaje de elaboración europea y que buscó impulsar en el nuevo continente (Pág. $68)$.

Por su lado en Parra (1999) se destaca que: "En la condición económica y social del monopolio y del pensamiento conservador reformista (impulsado por la Iglesia y la burguesía) se genera el espacio socio ocupacional del trabajador social" (Pág; 236).

El reformismo buscó también enfrentar, el planteamiento de movilización política que se generó desde el marxismo; el reformismo viene entonces a proponer un ajuste dentro del 
capitalismo, el cual se veía amenazado por las crisis cíclicas del modo de producción y la presión de ciertas fracciones de trabajadores y sus partidos políticos, algunos fundamentados en la obra de Marx, pero también en las bases anarquistas y/o socialistas utópicos.

\section{EI marxismo en el Trabajo Social}

Aparece en ese norte sincrético del Trabajo Social, especialmente en la Reconceptualización, otra tensión intelectual relevante que ya rondaba el continente como lo fue el marxismo, el cual viene a generar tensiones que son enfrentadas desde la escolástica, el positivismo y el reformismo, abriendo espacio para la presencia más numérica de los (as) fenomenólogos (as). Salazar (1988) destaca que el marxismo se expresa con mayor fuerza en los años treinta del siglo pasado, además cita:

Respecto al marxismo -y entrando en la consideración de las corrientes actuales- hay que decir que, aunque ha tenido importantes repercusiones políticas en los últimos años, con el establecimiento del régimen socialista de Cuba, informa toda la actividad intelectual y la cultura de un país, no ha sido la más influyente filosofía en las universidades, ni siquiera entre amplios sectores de escritores e intelectuales, aunque es sin duda la filosofía que más fuerte esfuerzo de vulgarización ha recibido [...] La influencia francesa [...] se reciben los más recientes aportes marxistas de Politzer, Lefebvre, Garaudy, Goldman y Althusser ${ }^{4},[\ldots]$ la alemana [...]; el marxismo y el pensamiento socialista en general, a través de la difusión de autores clásicos de esta línea doctrinaria, especialmente Marx y Engels, y de ciertos nombres contemporáneos como Ernst Bloch y Herbert Marcuse, $[\ldots]$ La filosofía italiana [...] la obra de marxistas como Labriola, Gramsci, Mondolfo y Della Volpe. [...] La influencia rusa $[\ldots]$ socialismo marxista de Plenájov,

\footnotetext{
${ }^{4}$ Althusser ha sido criticado en los círculos marxistas por su influencia positivista (Lowy, 1975), y estructuralista.
} 
Lenin, Trotski, Bujarin, Stalin [...] Hay, en fin, la acción aislada pero vigorosa de un filósofo húngaro, el marxista Georgy Luckács, [...] (págs. 23-27).

Es necesario citar que en la singularidad del Trabajo Social se identifica una fuerte presencia contemporánea que retoma las líneas originales, de la obra de Luckás y Gramsci, con referente fundamental en ciertas universidades de Brasil, especialmente en la Universidad Federada de Río de Janeiro, la Universidad Estadual de Río de Janeiro y la Universidad Pontifica de São Paulo; teniendo como dos expositores fundamentales en Trabajo Social a Marilda Iamamoto y José Paulo Netto.

En el caso particular del Trabajo Social en la época de la Reconceptualización, Quiroga (1991) destaca que se tuvo una importante contaminación del positivismo en la enseñanza de la metodología por la vía de las obras de Althusser, además de ello Netto (1989) señala:

Entiendo que el diálogo entre sectores del Servicio Social y la tradición marxista se configura a partir de la década del 60 , e involucrando de esta forma diferencial segmentos profesionales (notoriamente docentes) en algunas áreas capitalistas desarrolladas (América del Norte, Europa Occidental) y en muchas áreas capitalistas periféricas (con una especial presencia en América Latina) [...] (pág. 162).

Netto (1989) también comenta:

La resultante de este juego polifacético fue una aproximación muy peculiar de sectores del Servicio Social a la tradición marxista. Yo diría que ella se singularizó por tres trazos interligados. En primer lugar, se trató de una aproximación que se realizó bajo exigencias teóricas muy reducidas -las exigencias que la comandaban eran de naturaleza sobre todo ideo-política, con un cariz fuertemente instrumental comandando este diálogo. En 
segundo lugar, y consecuentemente, la referencia a la tradición marxista era muy selectiva y venía determinada más por su vinculación a determinadas perspectivas práctico-políticas y organizacional-partidarias que por la relevancia de su contribución crítico analítica. En fin, la aproximación no se dio a través de las fuentes marxianas y o de los "clásicos" de la tradición marxista, sino especialmente a través de divulgadores y por la vía de manuales de calidad y niveles discutibles (pág. 163).

El positivismo, como base del sincretismo, se materializó en el estudio del marxismo contaminándolo de las esencias de naturalización de las leyes que rigen la sociedad, la sobrevaloración de la economía como determinante de las relaciones sociales, las explicaciones endogenístas de la profesión en sus bases teórico metodológicas, y tiñendo el trabajo profesional de un romanticismo utópico. Quiroga (1991) agrega:

Al asumirse una visión voluntarista, conscientizadora, idealista, se abandona la perspectiva de la lucha de clases que implica determinaciones objetivas y subjetivas y que se constituye en uno de los pilares de la comprensión marxiana del movimiento real de la sociedad capitalista. Este mismo vaciamiento se da al privilegiarse aisladamente la determinación económica, pues eso lleva a una secundarización, o sea, a abstraer al hombre de su dimensión de sujeto histórico, poniendo a la sociedad como producto independiente de la acción de él, en una proposición en última instancia propia del positivismo: la de una 'sociedad regida por leyes naturales' (pág. 166).

No es un secreto universitario el reconocer que el marxismo fue perseguido en el continente, especialmente en los escenarios de los avances políticos de la clase trabajadora, mediante conquistas de luchas que trataron de ir conteniendo las formas de explotación, demandando además, servicios sociales que redujeran, en el mejor de los casos, las devastaciones de la "cuestión social". Dicha la 
lucha también se expresó en las llamadas democracias burguesas, teniendo reflejo en un fortalecimiento de partidos políticos que, en algunos casos, reflejaban intereses reales de ciertas fracciones trabajadoras; la llegada del socialismo en Chile con Salvador Allende fue un ejemplo claro; también estuvieron las batallas sociales logradas a lo largo del continente.

Por otro lado, la persecución estatal, de quienes lideraban las luchas sociales desde el marxismo, con ayuda de otros gobiernos, como el estadounidense, propició condiciones para que el lastre conservador reflejado en la fenomenología, se fortaleciera ${ }^{5}$ en el colectivo de Trabajo Social, aunque muchas veces de manera vulgar (Netto, 1996), aparece aquí otra tirantez en la base sincrética profesional.

\section{La fenomenología en Trabajo Social}

La fenomenología “en Hispanoamérica se sitúa alrededor de la década del treinta, por conducto de la fenomenología de Husserl y sus seguidores y del existencialismo de Heidegger y Jaspers" (Salazar, 1988: 24 y 25). Es difícil encontrar literatura sobre su presencia en el continente, y a lo que Trabajo Social refiere es aún más desafiante. Sin querer hacer una generalización para el resto del continente, se puede ilustrar la presencia de la fenomenología en el Trabajo Social con la siguiente cita:

El dato más sobresaliente de lo que propone innovador en los textos representativos de la tendencia renovadora que ahora tratamos es, sin duda, la reivindicación de un soporte

${ }^{5}$ No se concuerda en este texto cuando se cita que la fenomenología en el Trabajo Social, fue una respuesta ante el positivismo, nos parece más bien que fue un "no estudiar el marxismo", ello por la siguiente cita: "Trabajo Social en los últimos años - en la búsqueda de alternativas para dar respuestas a los problemas planteados por la matriz empírica positivista- ha venido proponiendo el enfoque fenomenológico como otra manera de investigar" (Matus et al, 1991: 29) 
metodológico hasta entonces inusual en el desarrollo del Servicio Social [...] el recurrir a la fenomenología aparece en ellos como el insumo para la reelaboración teórica y práctica de la profesión. Justamente, la demanda del aporte del pensamiento fenomenológico surge como la faceta más prominente de las colocaciones significativas de los autores que se inscriben en la perspectiva de reactualización y del conservadurismo (Netto, 1996: 208).

Un aporte que se puede dar de manera tentativa, para contextos de mayor influencia norteamericana, es la de identificar en la orientación terapéutica en el Trabajo Social, un lastre fenomenológico traído de los Estados Unidos, y que sincréticamente se constituyó en parte de las bases clínicas que se han hecho sentir provenientes del Social Work. Ionescu (2001) plantea que "la PSICOPATOLOGIA fenomenológica tiene sus orígenes en la filosofía alemana del mismo nombre [...] sobre todo después de la segunda Guerra Mundial, la fenomenología penetró en la América del Norte (pág.78). Además de ello, se encuentra la presencia del llamado "paradigma cualitativo" (principalmente kantiano), que se postula como una llamada base metodologísta, que a nuestro criterio tiene en la fenomenología y en la sociología comprensiva de Weber, parte de su cuna filosófica. De la herencia norteamericana, el Trabajo Social también heredó en su sincretismo el llamado pragmatismo, base esencial de la llamada filosofía de Estados Unidos, así como el protestantismo, sostén ideológico-religioso de importante expresión en dicho país; de ambos las investigaciones en su relación con el Trabajo Social son casi inexistentes.

\section{El pragmatismo en Trabajo Social}

La influencia norteamericana en la profesión se intensifica posterior a la consolidación de las escuelas pioneras en el continente, especialmente vía el papel asesor de la Organización de Naciones Unidas, que diseminaron con sus propuestas una 
importante base pragmática en el Trabajo Social, al respecto es importante destacar la siguiente definición:

Postura cuyo criterio de verdad consiste en identificarla con las consecuencias prácticas que reporta, es decir, que la verdad de una afirmación equivale a su utilidad. Fil. Aunque se habla de pragmatismo en la Antigüedad, como escuela filosófica surgió a fines del s. XX, en EE.UU, donde ha tenido a sus pensadores más destacados, a pesar de que no coincidan doctrinalmente. Su fundamento se halla en la famosa máxima del pragmatismo formulada por Charles S. Peirce: 'Concebimos el objeto atendiendo a efectos alcanzables prácticamente. La concepción de dichos efectos resulta así el conjunto de nuestra concepción del objeto'. Su difusión se debe a William James, (...) (Salvat, 2004: 12587).

El término se deriva de la palabra griega pragma, que quiere decir «acción», de las que vienen nuestras palabras «práctica» y «práctico». Fue introducido en la filosofía en 1878 y se caracteriza con argumentos tales como:

[...] Para lograr una perfecta claridad en nuestros pensamientos de un objeto, por consiguiente, necesitamos sólo considerar qué efectos concebibles de orden práctico puede implicar el objeto; qué sensaciones podemos esperar de él y que reacciones habremos de preparar. [...] Se vuelve hacia lo concreto y adecuado, hacia los hechos, y hacia la acción y el poder. Esto significa el predominio del temperamento empirista y el abandono de la actitud racionalista. [...] Está de acuerdo por ejemplo con el nominalismo en su apelación constante a los casos particulares; con el utilitarismo, en poner de relieve los aspectos prácticos; con el positivismo, en su desdén por las soluciones verbales, las cuestiones inútiles y las abstracciones metafísicas. [...] No supone resultados particulares, sino solamente una actitud de orientación, que 
es lo que significa el método pragmatista. La actitud de apartarse de las primeras cosas, principios, "categorías", supuestas necesidades, y de mirar hacia las cosas últimas, frutos, consecuencias, hechos (James, 2002: 46, 47, 49, $50,51)$.

Sobre el pragmatismo vale destacar que, por ser la profesión de Trabajo Social eminentemente interventiva en la "cuestión social", el mismo encuentra un terreno fértil en el trabajo profesional; aunado al espejismo inmediatista que puede generar. Teniendo de referencia el papel que jugó Estados Unidos en su proyecto imperialista en América Latina, asesorando, directa o indirectamente el establecimiento de Escuelas de Trabajo Social en nuestros países (Véase Castro, 1982), se puede destacar la inminente influencia del pragmatismo en esas "asesorías". Para Zamanillo y Gaitán (1997) el pragmatismo es muy bien expresado en el pensamiento pionero de Mary Richmond, citan las autoras:

Mary Ellen Richmond, que fue amiga de G.H. Mead y discípula de Dewey, [...] Hacia 1893 al darse cuenta de la escasez de conocimientos teóricos de las "visitadoras", comienza a estudiar sociología y filosofía, especialmente la obra de William James y John Dewey [...] (p. 34).

Pero el pragmatismo no llegó sólo, parte de la sociedad que lo consolidó, fortaleció consigo el protestantismo, que se infiltró en algunas expresiones de un Trabajo Social de una fuerte herencia católica conservadora.

\section{El protestantismo en Trabajo Social}

En lo que al protestantismo corresponde, vale anotar que se torna de interés citarlo, por las estrechas relaciones que tiene con la consolidación de la sociedad estadounidense, con el pragmatismo, con el capitalismo, con el conservadurismo, y por ende con el 
proyecto de Social Work que se deriva de ese país al resto del continente, también se destaca:

El nombre de protestantismo tiene su origen en la "protesta" presentada por los príncipes alemanes, simpatizantes con la Reforma, ante Carlos V [...] Las principales ramas actuales del protestantismo son: luteranismo (N. de Europa), calvinismo (Suiza, Francia), presbiterianismo (Escocia y EE.UU.) y anglicanismo (Gran Bretaña). El protestantismo nació en una coyuntura histórica favorable: decadencia de la ideología medieval y escolástica ante una nueva ciencia experimental, una estructura económica de tipo mercantil y una visión activa e individualista del hombre (Salvat, 2004: 12.748).

También es importante señalar que el protestantismo se empieza a consolidar en el continente en la segunda mitad del siglo XIX (Míguez, 1983: 21), este movimiento religioso se articula de forma estratégica con el pensamiento liberal que hace críticas a la Iglesia Católica, y se catapulta para ser una religión que se conjuga con cierto discurso de modernidad, o sea con la visión de consolidar una nación con el ejemplo de los Estados Unidos de América. El protestantismo se emparentó estratégicamente con el modo de producción capitalista, y por ende recibió el apoyo de los Estados laicos, además se cita:

La influencia liberal del momento hacía que las constituciones políticas permitieran la libertad de culto con lo cual la puerta se abría a la penetración religiosa protestante en un momento de expansión imperial del capitalismo norteamericano. Los Estados Unidos relevan a Inglaterra hacia fines del siglo XIX y se convierten en hegemónicos. Y en esta empresa militar y económica los misioneros protestantes jugaron un papel nada despreciable como legitimadores religiosos y como propagandistas. [...] los misioneros protestantes hicieron acto de presencia firme 
apoyados económicamente por Estados Unidos, [...] (Martínez y Samdú, 1990: 48).

Vale agregar lo siguiente:

También las élites perciben (con razón) a la Iglesia Católica Romana, como uno de los obstáculos básicos en el ingreso a la modernidad, en tanto que ven al Protestantismo como aliado, en parte por ser la religión de las sociedades tomadas como modelo, en parte por ser la religión de la libertad, del individualismo, el libre juicio, la educación. [...] En alianza con liberales y particularmente con masones, luchará por la libertad religiosa y distintas secularizaciones (cementerios, escuelas, registro civil) (Míguez, 1983:26 y 27).

Por la ausencia de investigaciones en el tema, es limitado lo que se puede escribir sobre el protestantismo en el Trabajo Social en América Latina, pero debe quedar constancia de que en aquellas naciones donde la influencia estadounidense se expandió, se traía consigo esta doctrina religiosa. A lo que Martínez y Samdú (1990) señalan: "Los protestantes [...] que siempre se habían caracterizado por la indiferencia en materia social, empezaron a proyectarse con decisión en el campo asistencial" (pág. 41).

La relación del protestantismo con la "cuestión social", tiene sus particularidades en las distintas regiones de América Latina. De acuerdo a Martínez y Samdú (1990): “[...] no sólo construían escuelas y ciertas obras sociales, sino que organizaban las llamadas Carabanas de Buena Voluntad, en las que combinaba la predicación con la entrega de ciertos beneficios asistenciales a la población destinataria del mensaje" (pág. 49).

Piedra (1990) cita lo siguiente sobre la relación del protestantismo con la "cuestión social": 
La gente sufre en carne propia las consecuencias de la falta de trabajo y de vivienda [...] Estas personas sufren los efectos de la injusticia social, requieren una atención inmediata [...] se encuentra en una religión militante que imprime una fuerza espiritual que hace más llevadera la situación de la miseria que viven los creyentes. La gran mayoría de la gente más pobre [...] no tiene seguridad social que le garantice la atención médica, y por ende, no tiene la posibilidad de gozar de una buena salud. [...] Lo antes citado hace que un mensaje cristiano que enfatice la sanidad divina tenga atractivo en una inmensa proporción de la población. [...] El protestantismo desde mucho tiempo atrás, viene predicando la doctrina que sustenta la idea, $[\ldots]$ de que el mero hecho de que una persona se convierta al protestantismo, le crea las posibilidades de un uso más racional de ingresos económicos. [...] Lo cierto del caso es que las prácticas como el alcoholismo y el consumo de otras drogas, acentúan la pobreza de quienes practican tales cosas. De allí que cuando una persona se convierte al protestantismo, automáticamente obtiene beneficios directos que van a ser fruto de una mejor administración del dinero que pueda disponer (págs. 291, 292 y 293).

Como se ha destacado, las posiciones liberales, positivistas y conservadoras, se impregnan en la relación del protestantismo con la "cuestión social"; y esto se pudo expresar tanto en la base teóricometodológica como ético-política que guió muchas de las interpretaciones conservadoras de las escuelas formadoras de trabajadores y trabajadoras sociales en el continente, aún así su investigación es todo un desafío.

\section{Eclecticismo en Trabajo Social}

Es necesario aclarar que sincretismo y eclecticismo son dos temas distintos, en este caso, se considera que el sincretismo que se expresa en el Trabajo Social, también permitió el avance de la 
propuesta ecléctica, la cual se entiende como: "Escuela filosófica de que procura conciliar las doctrinas que parecen mejores, o más verosímiles, de diversos sistemas" (Océano: 1990: 234).

El tema del eclecticismo, tiene una expresión que es histórica en los debates profesionales, pero su trato particular en la literatura en Trabajo Social, es casi inexistente. El eclecticismo se expresa de manera fuerte, en especial cuando hay pobres bases formativas y es usado de referencia vaga sobre el tema; vale citar lo siguiente:

El eclecticismo es propio también del revisionismo moderno. El principal defecto metodológico del eclecticismo estriba en su incapacidad para delimitar, en la suma de nexos y relaciones del mundo objetivo, los lazos fundamentales del objeto, del fenómeno, respecto al medio que lo circunda en un momento dado; estriba en unir mecánicamente las diversas partes y propiedades de los objetos o fenómenos. En la esfera de la actividad práctica y de la política, el eclecticismo conduce a fallas y errores, ya que impide hallar el eslabón principal en la cadena de acontecimientos, señalar las medidas que permitan resolver las tareas de mayor actualidad en un período concreto de la historia (Diccionario Soviético de Filosofía: 1965: 130).

En la discusión que se trae, se puede hablar de una orientación ecléctica, cuando el o la profesional cree que puede, establecer un método, eligiendo con libertad, lo "mejor" del positivismo, la fenomenología y el marxismo, por ejemplo.

El identificar qué es "lo mejor", como argumento del eclecticismo, es analizado como una valoración un tanto oportunista, y la gran mayoría de las veces inconsistente, donde los argumentos dados pueden no soportar su discusión académica, y se torna un mecanismo de defensa profesional, al tener cuestionamientos teóricos del fundamento del trabajo que se realiza. 


\section{A guisa de cierre}

Haciendo un cierre de este artículo, es importante recordar que los contenidos teóricos de las temáticas señaladas, pierden su esencia sino son develados en su papel en la historia y su vigencia hasta el momento, expresado de formas diversas y contradictorias. Además, los debates planteados son desafiantes para quien intente hacer "ruptura", con el sincretismo que ha sido base de la profesión, en especial, cuando nos situamos en la relación ético-política y teóricometodológica.

América Latina, es un continente muy diverso. Igual lo es la profesión de Trabajo Social, en relación a su historia, su consolidación y reproducción hasta el día de hoy; por lo cual, las tentaciones de la generalización se deben controlar, en especial cuando encontramos un sincretismo importante y de matices distintos. La presencia y hegemonía del positivismo, en sus diferentes expresiones, se expandió en una América Latina que tenía como referente la escolástica, ambos se articularon y convivieron, el capitalismo no ha sido punto de desacuerdo, incluso, les ha permitido articulaciones estratégicas de legitimación política y cultural.

Sus manifestaciones en el Trabajo Social fueron relevantes, no se debe olvidar que la preocupación burguesa y religiosa por la "cuestión social", ha sido histórica, y se reflejó en la constitución profesional que halló bases teórico-metodológicas y ético-metodológicas en el positivismo y la escolástica. El reformismo, producto interesante del pensamiento católico burgués, fue otro bastión importante dentro de los insumos en el Trabajo Social, ello porque las políticas sociales definieron ciertas orientaciones de intervención en la "cuestión social", que se proyectaba hacia la neutralización y la armonía de los conflictos sociales.

Sobre el marxismo, se aprecia que de las distintas influencias presentes en América Latina, y en el Trabajo Social propiamente, son rescatables en la medida en que se debatan con las fuentes originales del marxismo. Aún así, la historia ha reclamado una vulgarización positivista de la misma, que se localiza especialmente en algunas fracciones que se articulan al Movimiento de Reconceptualización. 
Este movimiento, también permitió que las personas que se oponían a sus planteamientos, con "reales intentos de ruptura", encontraran en la fenomenología una salida "modernizadora", pero sin alejarse del matiz positivista en el debate sobre teoría y metodología en Trabajo Social; esto porque la fenomenología, a pesar de sus críticas al racionalismo, no entra más que a interpretar el mundo; el conocido descubrimiento contemplativo; o en el mejor de los casos colocado en los aires reformistas.

La ausencia de investigaciones sobre el tema, aún lleva a tener muchas conjeturas, sobre los ejes tratados; una de ellas es la relación entre la llamada "intervención terapéutica" y la fenomenología, venida por la influencia del Social Work y otras corrientes europeas, en la cual también se expresan el protestantismo y el pragmatismo. El otro punto de relevancia es el protestantismo, que en los países de tendencia liberal, encontró una importante acogida, ya que legitimaba, tanto el proyecto imperialista norteamericano - la Iglesia Católica también lo hacía a su modo- , y lograba ser crítica al conservadurismo católico.

En el Trabajo Social, dice Netto (1990), el protestantismo fue base del Social Work en Estados Unidos y Canadá, sus lineamientos explicativos de la sociedad y de la "cuestión social", se impregnan y expandieron en el continente. Finalmente cabe destacar que el presente artículo pretendió dar una mirada muy general al tema, queda pendiente un acercamiento más particularizado en el contexto nacional, esfuerzo que debe desarrollarse de manera pronta, para lograr fortalecer el debate en la categoría profesional. 


\section{Referencias}

Augusto, Beatriz. (1995). Algunas considerações sobre Ética e Valor. En Dilsea Adeodata, et al. (1995). Serviço Social e Ética. São Paulo, Brasil: Edición Cortez- CEFSS.

Brand, Salvador. (1984). Diccionario de Economía. Santafé de Bogotá: Editorial Colombia.

Castro, Manuel y Iamamoto, Marilda (1979). Hacia el estudio de la historia del Trabajo Social en América Latina. Revista Acción Crítica, 5. Lima, Perú: CELATS.

Diccionario Soviético de Filosofía (1965). Montevideo, Uruguay: Ediciones Pueblos Unidos.

Iamamoto, Marilda. (1992). Servicio Social y División del Trabajo. São Paulo, Brasil: Editora Cortez.

Insua, Ramón. (1949). Historia de la filosofía en Hispanoamérica. Guayaquil, Ecuador: Universidad de Guayaquil.

Ionescu, Serban. (2001). Catorce enfoques de la psicopatología. México, D.F, México: Fondo de Cultura Económica.

James, William. (2002).Pragmatismo. Barcelona, España: Ediciones Folio.

Lowy, Michael (1975) Dialéctica y Revolución. México: Editorial Siglo XXI.

Mandel, Ernest. (1977). Iniciación a la economía marxista. España: Editorial Nova Terra.

Martinelli, María. (1997). Servicio Social: Identidad y Alineación. São Paulo, Brasil: Editora Cortez.

Martínez, Abelino y Samandú, Luis. (1990). Acerca del desafío pentecostal en Centroamérica. En Luis Samadú (Comp), Protestantismos y procesos sociales en Centroamérica. San José, Costa Rica: CSUCA. 
Matus, Teresa et al (1991) Perspectivas metodológicas en la formación de los trabajadores sociales en la actual coyuntura latinoamericana. Ponencia presentada en el Seminario Taller. Lima, Perú: ALAETS-CELATS.

Míguez, José. (1983). Historia y Misión: Los estudios históricos del cristianismo en América Latina con referencia a la búsqueda de liberación. En DEI, Protestantismos y liberalismo en América Latina. San José, Costa Rica: DEI- Seminario Bíblico Latinoamericano.

Netto, José. (1996). Ditadura e Serviço Social: Uma análise do Serviço Social no Brasil pós-64. São Paulo, Brasil: Editora Cortez.

Netto, José Paulo. (1992). Capitalismo Monopolista y Servicio Social. São Paulo, Brasil: Editora Cortez.

Netto, José. (1989). El Servicio Social y la tradición marxista. En Elizabete Borgianni, et al. (2003), Servicio Social Crítico. São Paulo, Brasil: Editora Cortez.

Nikin, P. (1969). Economía Política. México, D.F, México: Fondo de Cultura Popular.

Océano Uno (1990) Diccionario Enciclopédico. Madrid, España: Editorial Océano.

Parra, Gustavo. (1999). Antimodernidad y Trabajo Social. Luján, Argentina: Universidad Nacional de Luján.

Piedra, Arturo. (1990). Protestantismo y sociedad en Centroamérica. En Luis Samadú (Comp), Protestantismos y procesos sociales en Centroamérica. San José, Costa Rica: CSUCA.

Quiroga, Consuelo. (1991). Invasión positivista en el marxismo: el caso de la enseñanza de la metodología en el Servicio Social. En Elizabete Borgianni y Carlos Montaño (2000), Metodología y Servicio Social. São Paulo, Brasil: Editora Cortez.

Salazar, Augusto. (1988) ¿Existe una filosofía de nuestra América? México: Editores Siglo XXI. 
Salvat (2004) Enciclopedia. Madrid. España: Salvat Editores.

Soler, Ricaurte. (1979). Estudios sobre historia de las ideas en América. Ciudad de Panamá, Panamá: Librería Cultural Panameña.

Zea, Leopoldo. (1976). Filosofia y Culturas Latinoamericanas. México: Centro de Estudios Latinoamericanos Rómulo Gallegos. 